\title{
Correction to: Abnormalities of Aspiration and Swallowing Function in Survivors of Acute Respiratory Failure
}

\author{
Susan E. Langmore ${ }^{2}$ (1) - Gintas P. Krisciunas ${ }^{1,2} \cdot$ Heather Warner $^{4,5} \cdot$ S. David White ${ }^{12} \cdot$ Daniel Dvorkin $^{6,7}$. \\ Daniel Fink ${ }^{8}$. Edel McNally ${ }^{1,3}$. Rebecca Scheel ${ }^{10}$. Carrie Higgins ${ }^{6}$. Joseph E. Levitt ${ }^{9}$. Jeffrey McKeehan ${ }^{6}$. \\ Sandra Deane ${ }^{9} \cdot$ Jonathan M. Siner ${ }^{11} \cdot$ Rosemary Vojnik $^{9} \cdot$ Marc Moss $^{6}$
}

Published online: 26 February 2021

๑) Springer Science+Business Media, LLC, part of Springer Nature 2021

\section{Correction to: Dysphagia https://doi.org/10.1007/s00455-020-10199-8}

Due to the errors occurred in the originally published version, this article is being reprinted in its entirety as Correction. All errors have been corrected. It is the correct version.

\begin{abstract}
The mechanisms responsible for aspiration are relatively unknown in patients recovering from acute respiratory failure (ARF) who required mechanical ventilation. Though many conditions may contribute to swallowing dysfunction, alterations in laryngeal structure and swallowing function likely play a role in the development of aspiration. At four university-based tertiary medical centers, we conducted a prospective cohort study of ARF patients who required intensive care and mechanical ventilation for at least $48 \mathrm{~h}$. Within $72 \mathrm{~h}$ after extubation, a Flexible Endoscopic
\end{abstract}

The original article can be found online at https://doi.org/10.1007/ s00455-020-10199-8.

Susan E. Langmore

langmore@bu.edu

Boston Medical Center, Boston, MA, USA

2 Department of Otolaryngology, Boston University School of Medicine, Boston, MA, USA

3 Sargent College of Health and Rehabilitation Sciences, Boston University, Boston, MA, USA

4 Department of Surgery, Section of Otolaryngology, Yale School of Medicine, New Haven, CT, USA

5 Department of Communication Disorders, Southern Connecticut State University, New Haven, CT, USA

6 Division of Pulmonary Sciences and Critical Care Medicine, University of Colorado Denver, Aurora, CO, USA
Evaluation of Swallowing (FEES) examination was performed. Univariate and multivariable analyses examined the relationship between laryngeal structure and swallowing function abnormalities. Aspiration was the primary outcome, defined as a Penetration- Aspiration Scale (PAS) score of 6 or greater. Two other salient signs of dysphagia-bolus spillage/ swallow reaction time and residue-were secondary outcomes. A total of 213 patients were included in the final analysis. Aspiration was detected in 70 patients (33\%) on at least one bolus. The most commonly aspirated consistency was thin liquids (27\%). In univariate analyses, several abnormalities in laryngeal anatomy and structural movement were significantly associated with aspiration, spillage, and residue. In a multivariable analysis, the only variables that remained significant with aspiration were pharyngeal weakness (Odds ratio 2.57, 95\% CI 1.16-5.84, $\mathrm{p}=0.019$ ) and upper airway edema (Odds ratio 3.24, 95\% CI 1.44-7.66, $\mathrm{p}=0.004)$. These results demonstrated that dysphagia in ARF survivors is multi-factorial and characterized by both

7 The Bioinformatics CRO, Inc., Denver, USA

8 Department of Otolaryngology, University of Colorado Denver, Aurora, CO, USA

9 Division of Physical Medicine and Rehabilitation, Stanford University, Stanford, CA, USA

10 Division of Speech Language Pathology, Spaulding Rehabilitation Hospital, Boston, MA, USA

11 Section of Pulmonary, Critical Care, and Sleep Medicine, Yale University School of Medicine, New Haven, CT, USA

12 Rehabilitation Therapy Services, University of Colorado Hospital, Aurora, CO, USA 
anatomic and physiologic abnormalities. These findings may have important implications for the development of novel interventions to treat dysphagia in ARF survivors.

ClinicalTrials.gov Identifier: NCT02363686.

\section{Keywords}

Aspiration $\cdot$ Dysphagia $\cdot$ Acute respiratory failure $\cdot$ Mechanical ventilation critical care

\section{Introduction}

Each year more than 700,000 patients develop acute respiratory failure (ARF) requiring mechanical ventilation $[1,2]$. As they recover, most of these patients are extubated and eventually discharged from the hospital. One previously underrecognized consequence of ARF is post-extubation dysphagia and subsequent aspiration [3,4]. More than $30 \%$ of ARF survivors aspirate when formally tested and many still have dysphagia at the time of hospital discharge [3-14]. Aspiration is associated with many deleterious consequences including pneumonia, percutaneous feeding tube placement, long term care facility admission, and increased mortality [3-5, 14],

Though there are likely many mechanisms responsible for aspiration in ARF survivors, abnormalities in laryngeal structure and swallowing function may play a central role in the development of aspiration. Weakness related to critical illness has been shown to impair a patient's ability to swallow [4, 15]. Previous research suggests that laryngeal trauma from the endotracheal tube and its persistent contact with the arytenoids and vocal folds may also cause dysphagia and subsequent aspiration $[4,6,8,10,16,17]$. Physiological measures such as delay in swallow initiation or slowed closure of the larynx may also be associated with dysphagia and aspiration $[8,18]$.

There is a paucity of studies that have examined abnormalities associated with dysphagia and subsequent aspiration in ARF survivors In order to further determine the mechanisms responsible for the development of dysphagia and aspiration in ARF survivors, we conducted a prospective multi-center cohort study and hypothesized that abnormalities in laryngeal structure and swallowing function would be associated with the development of aspiration as well as other clinically important signs of dysphagia, namely bolus spillage and residue.

\section{Methods}

We prospectively enrolled patients at four university-based tertiary medical centers. Patients were eligible if they were at least 18 years old, admitted to an intensive care unit (ICU), and had been mechanically ventilated with an endotracheal tube for longer than $48 \mathrm{~h}$. Exclusion criteria included preexisting history of dysphagia, contraindications to enteral nutrition, pre-existing or acute primary, central, or peripheral neuromuscular disorder, head and neck cancer or surgery, presence of a tracheostomy, coagulopathy resulting in uncontrolled nasal or pharyngeal bleeding, altered mentation prohibiting compliance with the procedures, and less than $72 \mathrm{~h}$ since the time of extubation. The patient or surrogate decision maker signed an informed consent form for participation, and this study was approved by the Institutional Review Board at each of the four centers.

After enrollment, chart review was performed and basic demographic information, APACHE II score, and Charlson Comorbidity Index were collected. The APACHE II (Acute Physiology And Chronic Health Evaluation II) is a severityof-disease classification system with a final score of 0 to 71 , with higher scores corresponding to more severe disease and a higher risk of death. It is determined within $24 \mathrm{~h}$ of admission to an intensive care unit (ICU) [19]. The Charlson Comorbidity Index is a weighted tool used to quantify a patient's burden of disease and predict 1 year survival after hospitalization for patients with specific comorbid conditions, including those experienced by the patients in this study [20]. Each condition is assigned a weight from 1 to 6 , with the summation producing the Charlson comorbidity score.

After enrollment, chart review was performed and basic demographic information, APACHE II score, and Charlson Comorbidity Index were collected. Within $72 \mathrm{~h}$ after extubation, a speech-language pathologist (SLP) performed a Flexible Endoscopic Evaluation of Swallowing (FEES). Before starting patient enrollment, every SLP examiner was trained by SEL to perform the FEES protocol as per the protocol listed in the Appendix, Table 1. FEES is a gold standard instrumental procedure to evaluate oropharyngeal dysphagia using flexible laryngoscopy [21]. All FEES examinations performed for this study were video recorded. Both fiberoptic and distal chip endoscopes were used across study sites. The patient was seated with the head of the bed elevated. Most patients could tolerate an upright position (208/213; the remaining 5 patients required semi-upright (approximately 45 degrees) because of body habitus, wounds, a femoral line in place, or other reason. At the discretion of the SLP and as dictated by individual institutional protocols, a limited amount $(0.2 \mathrm{ml})$ of topical lidocaine spray was administered intranasally before laryngoscopic insertion. This amount of lidocaine has been shown to increase patient comfort without altering swallow function [22]. Oxymetazoline (decongestant) was also used with some patients.

Using our standard FEES protocol, the SLP examined various aspects of upper airway structure and function prior to delivering food or liquid. These tasks comprise Part 1 of the exam. It includes an assessment of structural movements 
that may not be visible during swallowing with FEES (eg. glottic closure) but can be elicited and viewed during phonatory tasks. Part 1 also includes an assessment of secretions, and assessment of sensation, using the Touch Test [23-25]. Subsequently, the SLP directly assessed swallowing function with a standardized set of food and liquid trials (Part 2 of the exam). The following bolus consistencies were given: ice chips, thin liquid (water), nectar thick liquid, puree (applesauce), and a cracker. All boluses were dyed green; water had additional white food coloring to enhance visibility. After each swallow, the laryngoscope was advanced to closely view the laryngeal vestibule and sub-glottis before recording the results of that trial. If necessary, patients could drink sips of water between trials to clear any remaining residue. If aspiration was noted on any bolus, that consistency was stopped and the protocol moved to the next consistency. The complete FEES Protocol, including Part 1 and 2 components, can be found in the Appendix 1 .

\section{Scoring the FEES Exam}

An independent rater (SEL) with over 30 years of FEES experience, was blinded to the identity of the patient. This rater scored every FEES examination. The different components of the FEES examination that were scored are summarized in the Appendix 2. In addition, an independent otolaryngologist (DF) scored 3 variables related to laryngeal pathology: vocal fold mobility, presence of laryngeal edema, and presence of granulation tissue on the vocal folds. A third person (RS) scored a portion of the exams to determine inter-rater reliability (IRR) with the primary rater. The accuracy was $75 \%(15 / 20)$ with a kappa value of 0.432 .

When scoring Part 1 and Part 2 of the exam, ratings of structural movements, sensation, secretions, and anatomical observations were grouped into five categories: (1) Velopharyngeal closure, base of tongue retraction, (2) Laryngeal elevation/valving/closure: epiglottic retroflexion, arytenoid/ lift, glottic closure, arytenoid mobility, vocal fold mobility; (3) Pharyngeal squeeze/medialization: reduced pharyngeal medialization; (4) Laryngeal Sensation: decreased sensation, presence of secretions; and (5) Laryngeal anatomical; presence of upper airway edema, granulation tissue.

When scoring Part 2 of the exam, where food and liquid were delivered, the following parameters were scored for every bolus that was swallowed: Swallow reaction or Spillage Time (\# of seconds from first visualization of the bolus entering the oropharynx until white-out caused by swallow onset), 'Anatomical Point of Lowest Spillage at Onset of the Swallow, Amount of Residue left after the swallow, (none/ trace, mild, moderate, severe), Residue Location, Patient Response to Residue, Penetration (Y/N), Aspiration (Y/N), Time of Penetration (before, during, after the swallow), Time of Aspiration (before, during, after the swallow) [26].
See Appendix 2 for details regarding scoring of the different components of the FEES examination.

Aspiration was our primary outcome of interest. For each bolus, time of aspiration (before, during, or after the swallow) and (2) score on the Penetration Aspiration Scale [27] were scored. A PAS score defines depth of airway invasion and the patient response. A PAS of 2-5 represents penetration into the laryngeal vestibule; a PAS score of 6-8 represents aspiration or passage of the bolus below the true vocal folds.

\section{Statistical Methods}

Normally distributed descriptive statistics were reported using mean and standard deviations. Non-normally distributed descriptive statistics were reported using median and $25-75 \%$ quartiles with ranges. Paired dichotomous data were analyzed using McNemar's test. Fisher's exact test was used for nominal dependent variables. Ordinal dependent variables were analyzed using the Wilcoxon Mann-Whitney exact test. We conducted individual univariate analyses testing the association between measurements of laryngeal pathology and swallowing function and aspiration for each patient. Only measurements of laryngeal pathology and swallowing function that were associated $(\mathrm{p}<0.1)$ with aspiration were entered into a multiple logistic regression analysis and were tested for interaction. There were no significant interactions in our analyses. Odds ratios (ORs) and $95 \%$ confidence intervals (CI) were determined for each independent variable in all multivariate logistic regression analyses. Specific pre-specified secondary analysis examined the association between edema and arytenoid mobility, and sensation and swallow reaction/ spillage time. In regard to residue, five variables were pre-specified and tested for their association with residue of puree and solid food: glottic closure, base of tongue retraction, pharyngeal medialization, epiglottic retroflexion, and vocal fold mobility. An alpha value of 0.05 was used for all statistical tests. Data was analyzed using JMP® Pro (Version 12.0.1, SAS Institute Inc., 2015).

\section{Results}

From August 2015 until July 2018, a total of 248 patients were consented. A total of 22 subjects withdrew from the study before the FEES exam was performed, and an additional 13 patients had incomplete FEES examinations. Therefore, a total of 213 patients were included in the final analysis (Fig. 1). Patient demographics are included in Table 1. Median age was 57 (interquartile range (IQR) 47-66) years; 131 patients (62\%) were male. Median admission APACHE II score was 19 (IQR 14-27), and median Charlson Comorbidity Index was 3 (IQR 2-6). The most 


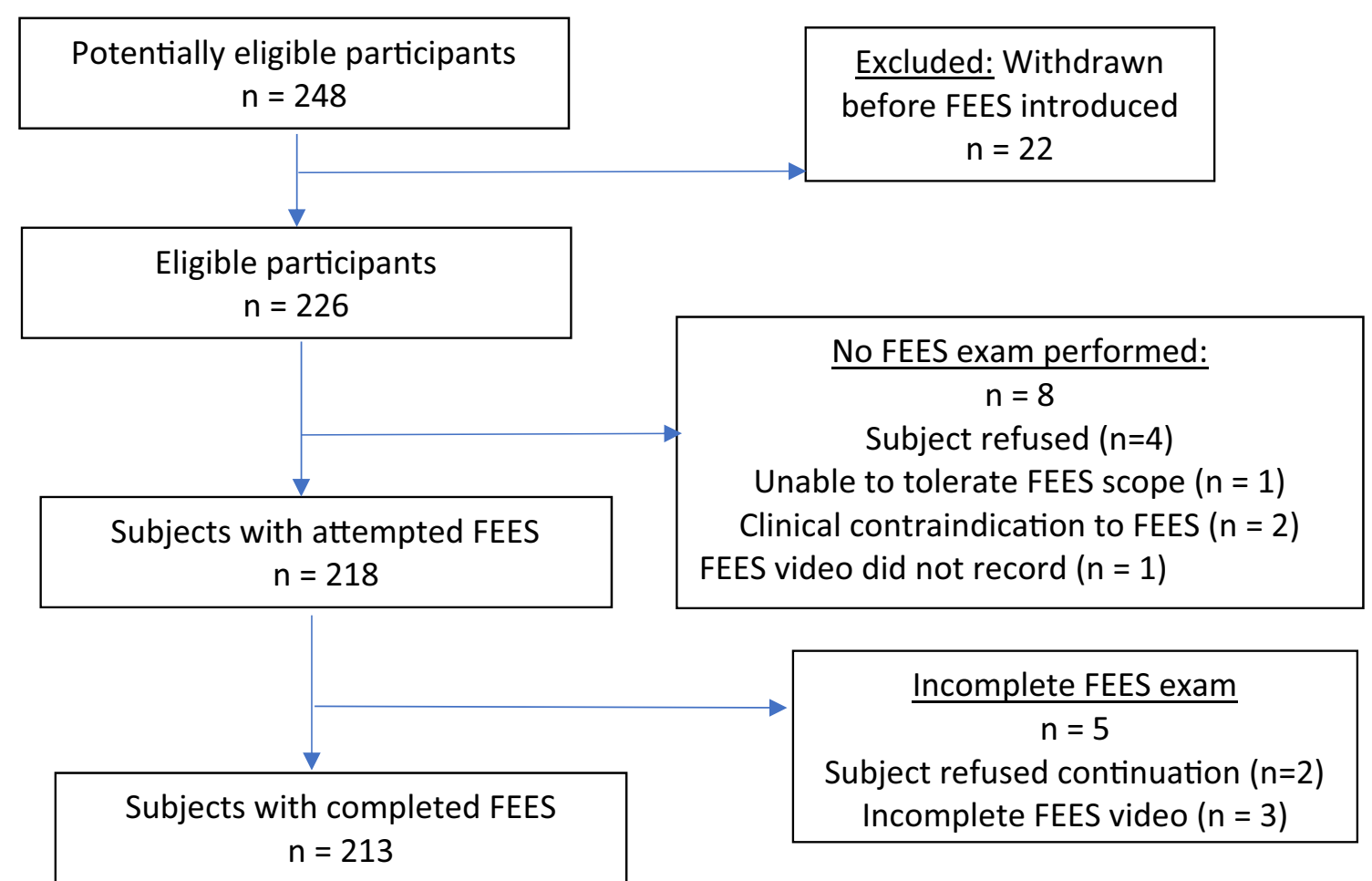

Fig. 1 Flow diagram

common co-morbidities were pulmonary and cardiac. Median duration of mechanical ventilation was 126 (IQR 72-205) h. Median time from extubation to the FEES was $26.5 \mathrm{~h}$ (IQR 22-47 h).

\section{Results of the FEES Examination: Penetration and Aspiration}

Almost all patients received at least one trial of each bolus consistency; ice $=100 \%(213 / 213)$; puree $=96.2 \%(205 / 213)$, nectar thick liquid $=98.6 \%(210 / 213)$, thin liquid $=92.5 \%$ $(197 / 213)$, and cracker $=82.6 \%(176 / 213)$. Penetration (PAS 2-5) was detected in 134 patients (63\%) and aspiration (PAS 6-8) was detected in 70 patients (33\%) on at least one bolus of any volume or consistency. A total of 29 (41\%) of these patients aspirated more than one consistency. Table 2 shows the percent of penetration and aspiration for each consistency. The most common consistency to penetrate and/or aspirate was thin liquids, followed by nectar thick liquids. Frequency and patterns of penetration and aspiration are shown in Table 2. For all consistencies, the most common time to penetrate was before the swallow, while aspiration usually occurred during the swallow, but this varied with the bolus consistency.

\section{Anatomic and Physiologic Correlates of Aspiration}

In univariate analyses, several measures of laryngeal anatomy and laryngeal/pharyngeal movement as scored in Part 1 and 2 of the exam were significantly associated with the overall presence of aspiration including: (1) Laryngeal elevation/valving/ closure: reduced glottic closure, incomplete epiglottic retroflexion, decreased arytenoid mobility, decreased vocal fold mobility; (2) Pharyngeal squeezel medialization: reduced pharyngeal medialization; (3) Laryngeal sensation: decreased sensation, secretions in the laryngeal vestibule; and (4) Laryngeal anatomical: presence of upper airway edema (usually arytenoid). Variables that were not significantly associated with aspiration were velopharyngeal closure, base of tongue retraction, arytenoid lift, and granulation tissue. In most cases, the same variables were significantly associated with aspiration, whether the bolus was ice/liquid or puree/nectars/solids Table 3 summarizes all these analyses. Further pre-specified analyses demonstrated that edema was significantly associated with reduced or absent arytenoid mobility $(\mathrm{p}<0.0001)$ (Appendix 3, Table 8). In a backwards elimination multivariable analysis that included glottic closure, pharyngeal medialization, epiglottic retroflexion, arytenoid mobility, secretions, edema, vocal cord mobility, and laryngeal sensation, the two variables that remained significant were pharyngeal medialization 
Table 1 Patient demographics $(\mathrm{N}=213)$

\begin{tabular}{|c|c|}
\hline Category & Distribution \\
\hline \multicolumn{2}{|l|}{ Site $^{\mathrm{a}}$} \\
\hline $\mathrm{BMC}$ & $97(46 \%)$ \\
\hline $\mathrm{UCH}$ & $75(35 \%)$ \\
\hline Stanford & $21(10 \%)$ \\
\hline Yale & $20(9 \%)$ \\
\hline Patient Age: median [IQR $]^{\mathrm{b}}$ & $57[47-66]$ years \\
\hline Gender (n, \% male) & $131(62 \%)$ \\
\hline \multicolumn{2}{|l|}{ Race } \\
\hline Caucasian & $117(55 \%)$ \\
\hline African American & $54(25 \%)$ \\
\hline Other & $42(20 \%)$ \\
\hline \multicolumn{2}{|l|}{ Primary service: $(\mathrm{n}, \%)^{\mathrm{c}}$} \\
\hline Medical ICU: & $147(69 \%)$ \\
\hline Cardiac ICU: & $45(21 \%)$ \\
\hline Surgical ICU: & $20(9 \%)$ \\
\hline Burn ICU: & $1(1 \%)$ \\
\hline \multicolumn{2}{|l|}{ Co-morbidity } \\
\hline COPD & $56(26 \%)$ \\
\hline Diabetes & $53(25 \%)$ \\
\hline Congestive heart failure & $46(22 \%)$ \\
\hline Myocardial infarction & $36(17 \%)$ \\
\hline Liver disease & $23(11 \%)$ \\
\hline Peripheral vascular disease & $19(9 \%)$ \\
\hline Dementia & $7(3 \%)$ \\
\hline Rheumatology disease & $5(2 \%)$ \\
\hline Peptic ulcer disease & $5(2 \%)$ \\
\hline Time from admission to intubation: median hours [IQR] & $8[0-48] \mathrm{h}$ \\
\hline Length of intubation: median hours [IQR] & $126[72-205] \mathrm{h}$ \\
\hline Charlson comorbidity Index (CCI): Median score [IQR] & $3[2-6]$ \\
\hline APACHE II score [IQR] & 19 [14-27] \\
\hline
\end{tabular}

${ }^{a} B U M C$ Boston University Medical Campus, $U C H$ University of Colorado Hospital

${ }^{\mathrm{b}} I Q R$ interquartile range

${ }^{\mathrm{c}} I C U$ intensive care unit

(Odds ratio 2.57, 95\% CI 1.16-5.84, $\mathrm{p}=0.019)$ and edema (Odds ratio 3.24, 95\% CI 1.44-7.66, $\mathrm{p}=0.004$ ).

\section{Results of the Exam: Spillage and Residue}

Bolus spillage was analyzed for two findings; swallow reaction time/ spillage time, and lowest point of bolus spillage. Depending on bolus consistency, median spillage times ranged from 0.7 to $2.5 \mathrm{~s}$ (IQR of $0-4.75 \mathrm{~s}$ ) (Table 4). The shortest median spillage time was observed with thin liquids and nectar thick liquids. This spillage time was closely associated with aspiration, but technically failed to reach significance: yes aspiration $=2.64 \mathrm{~s}( \pm 2.46)$ vs no aspiration $=2.04 \mathrm{~s}(+/=1.83), p=0.051$.
Table 5 shows the anatomical lowest point of spillage. Although No Spillage/None was the most common score, when it was seen, thin liquids spilled to either the valleculae or piriforms, while thicker liquids and more solid food usually fell only as far as the valleculae. A secondary analysis looked at possible factors associated with spillage and found that Reduced Sensation was significantly associated with Presence of Spillage of thin liquids $(\mathrm{p}=0.03)$. A further analysis showed that when sensation was reduced, the thin liquids were more likely to spill into the laryngeal vestibule $(\mathrm{p}=0.04)$, causing penetration. (Appendix 4, Table 9).

Residue was scored for ratings of amount of residue using an ordinal scale of none, mild, moderate, severe [26]. Table 6 shows the rating of amount of residue for ice/liquid and nectar/puree/solid consistencies. Of note, the categories 


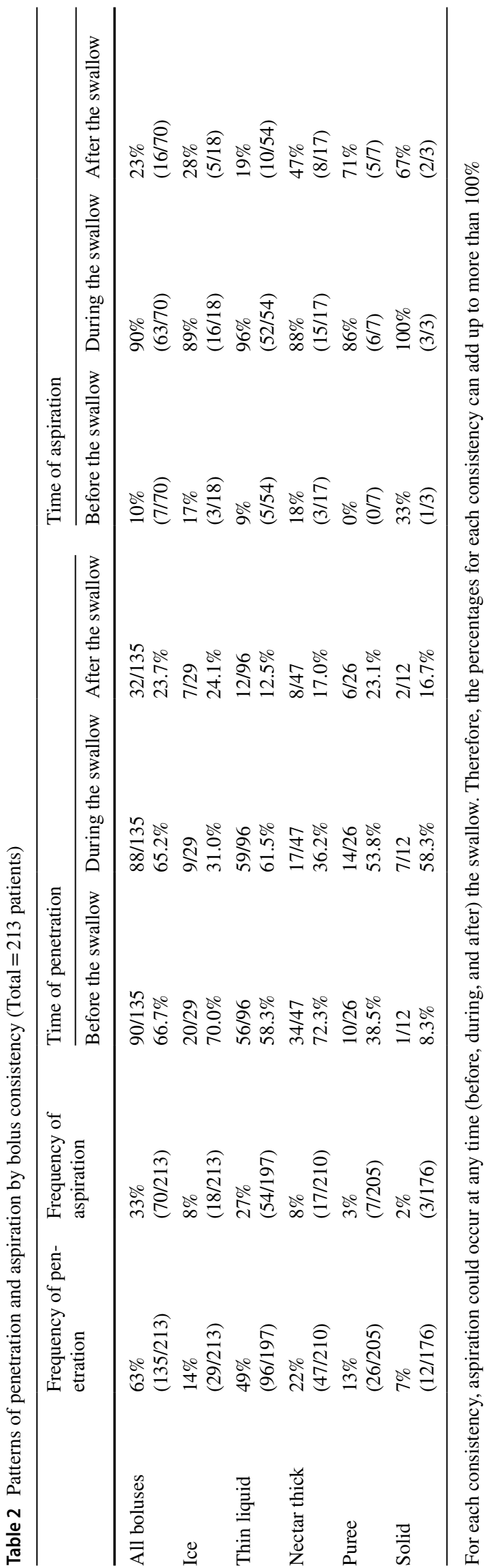

of moderate and severe were combined for the statistical analyses because there were so few instances of moderate or severe As can be seen, the most common ratings were 'none' or 'mild' amount of residue, for all consistencies. When looking for associations between laryngeal structure/swallowing function and residue for nectar thick liquid, puree, and cracker boluses, only Reduced Pharyngeal Medialization was significantly associated with the presence of residue $(\mathrm{p}=0.047)($ Table 7$)$.

\section{Discussion}

Dysphagia in ARF survivors is a complex diagnosis that is likely caused by multiple mechanisms. Limited definitive data on the specific mechanisms of dysphagia in this population is due to the heterogeneous nature of the methodology in the post-extubation dysphagia literature [28]. In this multi-center prospective study, we identified multiple abnormalities of laryngeal structure, sensation and swallowing physiology that were associated with aspiration, spillage, and residue in ARF survivors. Following a series of univariate analyses testing the association of multiple measured variables with aspiration, the two factors that remained significantly associated with aspiration in our multivariate analysis were reduced pharyngeal squeeze/medialization and upper airway edema. In a previous publication on this same cohort of patients, we reported that reduced laryngeal sensation was important in the development of dysphagia in certain ARF survivors [29]. In this current analysis, we determined that reduced laryngeal sensation was also associated with spillage into the laryngeal vestibule (ie, penetration) before the onset of the swallow. Finally, pharyngeal weakness was not only significantly associated with aspiration but it was also associated with the presence of residue after swallowing.

Based on results of the FEES examination, the overall mean incidence of aspiration in this large and well phenotyped cohort of patients was 30\% across the bolus consistencies. Published data on the frequency and type of aspiration in this patient population varies widely, however our findings are in general agreement with the majority of the reports in the literature [28].

This study identified several abnormalities in swallowing physiology that were associated with aspiration in ARF survivors. Knowledge about which components of swallowing function are associated with aspiration is critical for the practicing clinician. A significant association was shown to exist between aspiration and several components of laryngeal closure (epiglottic retroflexion, vocal fold and arytenoid immobility, glottic closure). This suggests the laryngeal movements needed to close the airway were impaired in this patient population. In addition, the significant association of 
Table 3 Association of anatomic abnormalities, sensation, secretions, and structural movements with aspiration

\begin{tabular}{|c|c|c|c|c|c|c|c|}
\hline & \multirow[t]{2}{*}{ Overall } & \multicolumn{2}{|c|}{ Positive for overall aspiration } & \multicolumn{2}{|c|}{$\begin{array}{l}\text { Positive for ice/thin liquids } \\
\text { aspiration }\end{array}$} & \multicolumn{2}{|c|}{$\begin{array}{l}\text { Positive for nectar/puree/ } \\
\text { solid aspiration }\end{array}$} \\
\hline & & Percent $(\mathrm{N})$ & $\mathrm{P}$ value & Percent $(\mathrm{N})$ & $\mathrm{P}$ value & Percent (N) & $\mathrm{p}$ value \\
\hline \multicolumn{8}{|l|}{ Velopharyngeal closure } \\
\hline Yes & $\begin{array}{l}97.0 \% \\
(191 / 197)\end{array}$ & $\begin{array}{l}33.0 \% \\
(63 / 191)\end{array}$ & 0.40 & $\begin{array}{l}30.4 \% \\
(58 / 191)\end{array}$ & 0.32 & $\begin{array}{l}10.0 \% \\
(19 / 189)\end{array}$ & 0.63 \\
\hline No & $\begin{array}{l}3.0 \% \\
(6 / 197)\end{array}$ & $\begin{array}{l}50 \% \\
(3 / 6)\end{array}$ & & $\begin{array}{l}50.0 \% \\
(3 / 6)\end{array}$ & & $\begin{array}{l}16.7 \% \\
(1 / 6)\end{array}$ & \\
\hline \multicolumn{8}{|l|}{ Base of tongue retraction } \\
\hline Yes & $\begin{array}{l}96.1 \% \\
(174 / 181)\end{array}$ & $\begin{array}{l}33.3 \% \\
(58 / 174)\end{array}$ & 0.21 & $\begin{array}{l}30.5 \% \\
(53 / 174)\end{array}$ & 0.15 & $\begin{array}{l}10.5 \% \\
(18 / 172)\end{array}$ & 0.22 \\
\hline No & $\begin{array}{l}3.9 \% \\
(7 / 181)\end{array}$ & $\begin{array}{l}57.1 \% \\
(4 / 7)\end{array}$ & & $\begin{array}{l}57.1 \% \\
(4 / 7)\end{array}$ & & $\begin{array}{l}0 \% \\
(0 / 7)\end{array}$ & \\
\hline \multicolumn{8}{|l|}{ Glottic closure } \\
\hline Yes & $\begin{array}{l}90.1 \% \\
(189 / 208)\end{array}$ & $\begin{array}{l}28.6 \% \\
(54 / 189)\end{array}$ & 0.002 & $\begin{array}{l}25.4 \% \\
(48 / 189)\end{array}$ & 0.0005 & $\begin{array}{l}7.5 \% \\
(14 / 189)\end{array}$ & 0.004 \\
\hline No & $\begin{array}{l}9.1 \% \\
(19 / 208)\end{array}$ & $\begin{array}{l}63.2 \% \\
(12 / 19)\end{array}$ & & $\begin{array}{l}63.2 \% \\
(12 / 19)\end{array}$ & & $\begin{array}{l}27.8 \% \\
(5 / 19)\end{array}$ & \\
\hline \multicolumn{8}{|l|}{ Epiglottic retroflexion } \\
\hline Normal & $\begin{array}{l}72.2 \% \\
(135 / 187)\end{array}$ & $\begin{array}{l}26.7 \% \\
(36 / 135)\end{array}$ & 0.04 & $\begin{array}{l}23.7 \% \\
(32 / 135)\end{array}$ & 0.02 & $\begin{array}{l}5.9 \% \\
(8 / 135)\end{array}$ & 0.01 \\
\hline Reduced & $\begin{array}{l}19.3 \% \\
(36 / 187)\end{array}$ & $\begin{array}{l}36.1 \% \\
(13 / 36)\end{array}$ & & $\begin{array}{l}33.3 \% \\
(12 / 36)\end{array}$ & & $\begin{array}{l}17.1 \% \\
(6 / 35)\end{array}$ & \\
\hline Absent & $\begin{array}{l}8.6 \% \\
(16 / 187)\end{array}$ & $\begin{array}{l}56.3 \% \\
(9 / 16)\end{array}$ & & $\begin{array}{l}56.3 \% \\
(9 / 16)\end{array}$ & & $\begin{array}{l}25.0 \% \\
(4 / 16)\end{array}$ & \\
\hline \multicolumn{8}{|l|}{ Arytenoid lift } \\
\hline complete & $\begin{array}{l}34.6 \% \\
(56 / 162)\end{array}$ & $\begin{array}{l}26.8 \% \\
(15 / 56)\end{array}$ & 0.23 & $\begin{array}{l}25.0 \% \\
(14 / 56)\end{array}$ & 0.41 & $\begin{array}{l}8.9 \% \\
(5 / 56)\end{array}$ & 0.75 \\
\hline Reduced & $\begin{array}{l}65.4 \% \\
(106 / 162)\end{array}$ & $\begin{array}{l}35.9 \% \\
(38 / 106)\end{array}$ & & $\begin{array}{l}31.3 \% \\
(33 / 106)\end{array}$ & & $\begin{array}{l}10.5 \% \\
(11 / 105)\end{array}$ & \\
\hline \multicolumn{8}{|c|}{ Pharyngeal squeeze/medialization } \\
\hline Normal & $\begin{array}{l}48.1 \% \\
(76 / 158)\end{array}$ & $\begin{array}{l}22.4 \% \\
(17 / 76)\end{array}$ & $<0.0001$ & $\begin{array}{l}19.8 \% \\
(15 / 76)\end{array}$ & $<0.0007$ & $\begin{array}{l}2.6 \% \\
(2 / 76)\end{array}$ & 0.0004 \\
\hline Reduced & $\begin{array}{l}37.3 \% \\
(59 / 158)\end{array}$ & $\begin{array}{l}40.7 \% \\
(24 / 59)\end{array}$ & & $\begin{array}{l}35.6 \% \\
(21 / 59)\end{array}$ & & $\begin{array}{l}37.6 \% \\
(9 / 59)\end{array}$ & \\
\hline Absent & $\begin{array}{l}14.6 \% \\
(23 / 158)\end{array}$ & $\begin{array}{l}65.2 \% \\
(15 / 23)\end{array}$ & & $\begin{array}{l}60.9 \% \\
(14 / 23)\end{array}$ & & $\begin{array}{l}31.8 \% \\
(7 / 22)\end{array}$ & \\
\hline \multicolumn{8}{|l|}{ Arytenoid mobility } \\
\hline Normal & $\begin{array}{l}81.1 \% \\
(167 / 206)\end{array}$ & $\begin{array}{l}27.5 \% \\
(46 / 167)\end{array}$ & 0.004 & $\begin{array}{l}24.0 \% \\
(40 / 167)\end{array}$ & 0.0008 & $\begin{array}{l}6.7 \% \\
(11 / 167)\end{array}$ & 0.002 \\
\hline Reduced & $\begin{array}{l}15.0 \% \\
(31 / 206)\end{array}$ & $\begin{array}{l}45.2 \% \\
(14 / 31)\end{array}$ & & $\begin{array}{l}45.2 \% \\
(14 / 31)\end{array}$ & & $\begin{array}{l}19.4 \% \\
(6 / 31)\end{array}$ & \\
\hline Absent & $\begin{array}{l}4 \% \\
(8 / 206)\end{array}$ & $\begin{array}{l}75 \% \\
(6 / 8)\end{array}$ & & $\begin{array}{l}75 \% \\
(6 / 8)\end{array}$ & & $\begin{array}{l}37.5 \% \\
(3 / 8)\end{array}$ & \\
\hline \multicolumn{8}{|l|}{ Vocal fold mobility } \\
\hline Normal & $\begin{array}{l}78.4 \% \\
(167 / 213)\end{array}$ & $\begin{array}{l}29.3 \% \\
(49 / 167)\end{array}$ & 0.04 & $\begin{array}{l}27.0 \% \\
(45 / 167)\end{array}$ & 0.06 & $\begin{array}{l}6.7 \% \\
(31 / 167)\end{array}$ & 0.003 \\
\hline Abnormal & $\begin{array}{l}21.6 \% \\
(46 / 213)\end{array}$ & $\begin{array}{l}45.7 \% \\
(21 / 46)\end{array}$ & & $\begin{array}{l}41.3 \% \\
(19 / 46)\end{array}$ & & $\begin{array}{l}21.7 \% \\
(10 / 46)\end{array}$ & \\
\hline \multicolumn{8}{|l|}{ Secretions } \\
\hline Normal & $\begin{array}{l}46.2 \% \\
(98 / 208)\end{array}$ & $\begin{array}{l}24.0 \% \\
(23 / 96)\end{array}$ & 0.002 & $\begin{array}{l}20.8 \% \\
(20 / 96)\end{array}$ & 0.0007 & $\begin{array}{l}4.2 \% \\
(4 / 95)\end{array}$ & 0.03 \\
\hline Pooled outside vestibule & $\begin{array}{l}49.5 \% \\
(103 / 208)\end{array}$ & $\begin{array}{l}36.9 \% \\
(38 / 103)\end{array}$ & & $\begin{array}{l}34.0 \% \\
(35 / 103)\end{array}$ & & $\begin{array}{l}15.5 \% \\
(16 / 103)\end{array}$ & \\
\hline
\end{tabular}


Table 3 (continued)

\begin{tabular}{|c|c|c|c|c|c|c|c|}
\hline & \multirow[t]{2}{*}{ Overall } & \multicolumn{2}{|c|}{ Positive for overall aspiration } & \multicolumn{2}{|c|}{$\begin{array}{l}\text { Positive for ice/thin liquids } \\
\text { aspiration }\end{array}$} & \multicolumn{2}{|c|}{$\begin{array}{l}\text { Positive for nectar/puree/ } \\
\text { solid aspiration }\end{array}$} \\
\hline & & Percent $(\mathrm{N})$ & $\mathrm{P}$ value & Percent $(\mathrm{N})$ & $P$ value & Percent $(\mathrm{N})$ & $\mathrm{p}$ value \\
\hline Pooled inside vestibule & $\begin{array}{l}4.3 \% \\
(9 / 208)\end{array}$ & $\begin{array}{l}77.8 \% \\
(7 / 9)\end{array}$ & & $\begin{array}{l}77.8 \% \\
(7 / 9)\end{array}$ & & $\begin{array}{l}12.5 \% \\
(1 / 9)\end{array}$ & \\
\hline \multicolumn{8}{|l|}{ Edema } \\
\hline No & $\begin{array}{l}44.1 \% \\
(94 / 213)\end{array}$ & $\begin{array}{l}18.1 \% \\
(17 / 94)\end{array}$ & $<0.0001$ & $\begin{array}{l}17.0 \% \\
(16 / 94)\end{array}$ & 0.0002 & $\begin{array}{l}1 \% \\
(1 / 94)\end{array}$ & 0.0001 \\
\hline Yes & $\begin{array}{l}55.9 \% \\
(119 / 213)\end{array}$ & $\begin{array}{l}44.5 \% \\
(53 / 119)\end{array}$ & & $\begin{array}{l}40.3 \% \\
(48 / 119)\end{array}$ & & $\begin{array}{l}17.0 \% \\
(20 / 119)\end{array}$ & \\
\hline \multicolumn{8}{|l|}{ Granulation tissue } \\
\hline No & $\begin{array}{l}42.7 \% \\
(91 / 213)\end{array}$ & $\begin{array}{l}34.1 \% \\
(31 / 91)\end{array}$ & 0.74 & $\begin{array}{l}30.8 \% \\
(28 / 91)\end{array}$ & 0.84 & $\begin{array}{l}9.0 \% \\
(8 / 89)\end{array}$ & 0.69 \\
\hline Yes & $\begin{array}{l}57.3 \% \\
(122 / 213)\end{array}$ & $\begin{array}{l}32.0 \% \\
(39 / 122)\end{array}$ & & $\begin{array}{l}29.5 \% \\
(36 / 122)\end{array}$ & & $\begin{array}{l}10.7 \% \\
(13 / 122)\end{array}$ & \\
\hline \multicolumn{8}{|l|}{ Sensation } \\
\hline Normal & $\begin{array}{l}55.8 \% \\
(101 / 181)\end{array}$ & $\begin{array}{l}22.8 \% \\
(23 / 101)\end{array}$ & 0.03 & $\begin{array}{l}22.8 \% \\
(23 / 101)\end{array}$ & 0.12 & $\begin{array}{l}3.0 \% \\
(3 / 101)\end{array}$ & 0.004 \\
\hline Unilateral deficits & $\begin{array}{l}21.6 \% \\
(39 / 181)\end{array}$ & $\begin{array}{l}43.6 \% \\
(17 / 39)\end{array}$ & & $\begin{array}{l}38.5 \% \\
(15 / 39)\end{array}$ & & $\begin{array}{l}12.8 \% \\
(5 / 39)\end{array}$ & \\
\hline Bilateral deficits & $\begin{array}{l}22.6 \% \\
(41 / 181)\end{array}$ & $\begin{array}{l}39.0 \% \\
(16 / 41)\end{array}$ & & $\begin{array}{l}34.2 \% \\
(14 / 41)\end{array}$ & & $\begin{array}{l}19.5 \% \\
(8 / 41)\end{array}$ & \\
\hline
\end{tabular}

Table 4 Swallow Reaction Time/ Spillage time in seconds (time bolus appears in oropharynx until white out): median [25-75\% quartiles], mean with $\mathrm{SD}$, and range

\begin{tabular}{llllll}
\hline & Ice & Thin liquids & Nectar-thick liquid & Puree & Cracker \\
\hline Swallow reaction time/spillage time (in s) & $2.5[1-5]$ & $0.7[0.3-1]$ & $0.7[0.3-2]$ & $1[0-2]$ & $1.9 \pm 2.7$ \\
& $3.5 \pm 3.6$ & $0.9 \pm 1.1$ & $1.6 \pm 2.7$ & $6.5 \pm 21.1$ \\
& Range 0-22 & Range 0-7 & Range 0-25 & $\begin{array}{l}\text { Range 0-25 } \\
(\mathrm{n}=204)\end{array}$ & $\begin{array}{l}\text { Range 0-240 } \\
(\mathrm{n}=176)\end{array}$ \\
\hline
\end{tabular}

Table 5 Anatomical point of lowest bolus spillage

\begin{tabular}{lcc}
\hline Point of lowest spillage & Ice/thin liquids (\%) & $\begin{array}{l}\text { Nectar/ } \\
\text { puree/solid } \\
(\%)\end{array}$ \\
\hline Valleculae & 21.1 & 35.9 \\
Lateral channels & 6.6 & 5.3 \\
Piriform/post cricoid & 27.4 & 13.1 \\
Laryngeal vestibule & 10.3 & 4.7 \\
No spillage & 34.6 & 41.0 \\
\hline
\end{tabular}

Table 6 Amount of residue

\begin{tabular}{lcl}
\hline Amount of residue & Ice/thin liquids (\%) & $\begin{array}{l}\text { Nectar/ } \\
\text { puree/solid } \\
(\%)\end{array}$ \\
\hline None/trace & 44.6 & 39.2 \\
Mild & 50.9 & 51.6 \\
Moderate/severe & 4.5 & 9.2 \\
\hline
\end{tabular}

pharyngeal medialization with both aspiration and mild to severe residue suggests that the large pharyngeal muscles may be indicative of general weakness including both the pharyngeal and laryngeal muscles.

The association of reduced pharyngeal medialization with residue is well known. A reduced Pharyngeal Squeeze maneuver directly reveals reduced pharyngeal strength [30]. Similarly, the association of reduced epiglottic retroflexion, reduced vocal fold and arytenoid immobility, and reduced glottic closure with penetration and aspiration reflect incomplete laryngeal valving. These two musculature systemspharyngeal and laryngeal muscles-work together to clear the bolus through the pharynx and keep it out of the airway. There are also several muscles that interface between the two major forces, including the stylopharyngeus, palatopharyngeus, and salpingopharyngeus. These muscles have a synergistic role, assisting or facilitating the major agonist muscles and during swallowing all these muscles are active [31]. Thus one can assume that there is a general weakness, 
Table 7 Association between selected physiologic variables and residue

\begin{tabular}{|c|c|c|c|}
\hline & $\begin{array}{l}\text { Puree/solid } \\
\text { residue: } \\
\text { none }\end{array}$ & $\begin{array}{l}\text { Puree/solid residue } \\
\text { mild/moderate/ } \\
\text { severe }\end{array}$ & $\mathrm{p}$ value \\
\hline Glottic closure & & & 0.70 \\
\hline Yes & $\begin{array}{l}35.3 \% \\
(6 / 17)\end{array}$ & $\begin{array}{l}64.7 \% \\
(11 / 17)\end{array}$ & \\
\hline No & $\begin{array}{l}39.9 \% \\
(73 / 183)\end{array}$ & $\begin{array}{l}60.1 \% \\
(110 / 183)\end{array}$ & \\
\hline $\begin{array}{l}\text { Base of tongue retrac- } \\
\text { tion }\end{array}$ & & & 0.30 \\
\hline Present & $\begin{array}{l}37.5 \% \\
(63 / 168)\end{array}$ & $\begin{array}{l}62.5 \% \\
(105 / 168)\end{array}$ & \\
\hline Absent & $\begin{array}{l}57.1 \% \\
(4 / 7)\end{array}$ & $\begin{array}{l}42.9 \% \\
(3 / 7)\end{array}$ & \\
\hline \multicolumn{4}{|l|}{$\begin{array}{l}\text { Pharyngeal medializa- } \\
\text { tion }\end{array}$} \\
\hline Normal & $\begin{array}{l}43.4 \% \\
(33 / 76)\end{array}$ & $\begin{array}{l}56.6 \% \\
(43 / 76)\end{array}$ & 0.047 \\
\hline Reduced & $\begin{array}{l}36.2 \% \\
(21 / 58)\end{array}$ & $\begin{array}{l}63.8 \% \\
(37 / 58)\end{array}$ & \\
\hline Absent & $\begin{array}{l}15.0 \% \\
(3 / 20)\end{array}$ & $\begin{array}{l}85.0 \% \\
(17 / 20)\end{array}$ & \\
\hline Vocal fold mobility & & & 0.95 \\
\hline Normal & $\begin{array}{l}38.7 \% \\
(63 / 163)\end{array}$ & $\begin{array}{l}61.3 \% \\
(100 / 163)\end{array}$ & \\
\hline Abnormal & $\begin{array}{l}38.1 \% \\
(16 / 42)\end{array}$ & $\begin{array}{l}61.9 \% \\
(26 / 42)\end{array}$ & \\
\hline Epiglottic retroflexion & & & 0.45 \\
\hline Normal & $\begin{array}{l}41.1 \% \\
(56 / 133)\end{array}$ & $\begin{array}{l}57.9 \% \\
(77 / 133)\end{array}$ & \\
\hline Reduced & $\begin{array}{l}36.4 \% \\
(12 / 33)\end{array}$ & $\begin{array}{l}63.6 \% \\
(21 / 33)\end{array}$ & \\
\hline Absent & $\begin{array}{l}26.7 \% \\
(4 / 15)\end{array}$ & $\begin{array}{l}73.3 \% \\
(11 / 15)\end{array}$ & \\
\hline
\end{tabular}

including both pharyngeal and laryngeal muscles, contributing to both aspiration and residue.

Anatomical factors related to aspiration are critical in this population. During the intubation procedure, the arytenoids and vocal folds can incur trauma and impair their ability to protect the airway during swallowing. In a related publication on this same cohort of patients, we found that an endotracheal tube (ETT) size of 8.0 or greater and longer duration of intubation were each significantly associated with subsequent aspiration [32]. The present study further investigated the impact of intubation and identified significant associations between edema and aspiration, reduced sensation and aspiration, and between laryngeal edema and reduced vocal fold or arytenoid mobility (Appendix 3, Table 8). A possible explanation for these many associations is that the endotracheal (ET) tube causes edematous arytenoids which will have reduced sensation and reduced mobility, making it more difficult for them to seal off the airway $[6,33]$. These statistical relationships suggest specific anatomic reasons for aspiration in this patient population.

Finally, we identified abnormalities related to timing at the onset of the swallow that were associated with aspiration. A very frequent pattern was for the bolus to penetrate the laryngeal vestibule before the laryngeal valve closed (arytenoids, epiglottis, and vocal folds). This abnormal pattern suggests a delayed laryngeal response to the impending bolus. These findings are consistent with a recent study of fluoroscopic dysphagia evaluations of ARF patients, where laryngeal valving (seen by delayed arytenoid movement) was reported to be slow or delayed [18]. Median liquid spillage times were not excessively long for many of the patients, although there were obvious patient outliers in this measure [34-36]. However, we did find that reduced sensation was significantly more likely to result in penetration, presumably because the larynx did not detect the impending bolus before it entered the laryngeal vestibule. In about a third of the swallows, the penetrated bolus continued its path into the laryngeal vestibule and was subsequently aspirated (Appendix 4, Table 9). We theorize that in those cases, edema and subsequent reduced mobility caused the arytenoids to be deficient in moving quickly and effectively to cover the glottis. Thus, evidence from this study for the 'delayed' onset of laryngeal closure supports the role of reduced sensation, edema, and reduced arytenoid mobility, all contributing to the subsequent penetration and aspiration.

This study has several strengths. This multi-center trial followed a standard protocol and scoring system, with an external rater of the FEES exams who was not familiar with the patients. The number of subjects was also large enough to strengthen our findings. To our knowledge, this is the first study to specifically analyze the multiple abnormalities causing aspiration, spillage, and residue in this specific population of ARF survivors without pre-existing dysphagia. This study also has several limitations. This study was a cross sectional study of one point in time, and did not look at recovery. Therefore, we cannot address the question of when to evaluate the patients. The many significant associations found do not necessarily imply causation. While this study focused on direct, intrinsic causes of penetration and aspiration, it did not consider the impact of the extrinsic causes of dysphagia such as general weakness, debilitation, and level of alertness. Finally, the IRR was lower than hoped, suggesting a need to standardize the scoring of FEES exams. We hope to pursue this in future research.

In summary, multiple signs of dysphagia, most importantly, aspiration, are common in ARF patients without preexisting dysphagia. This study has begun to elucidate the 
anatomical and functional changes associated with dysphagia and aspiration in the ARF survivor patient population. These results lend support to the hypothesis that the mechanisms responsible for dysphagia and aspiration in ARF survivors are multifactorial and provide critically important information that will begin to guide practicing clinicians in evidence-based clinical decision making about the management of dysphagia in this patient population. This study provides an important foundation for future studies that should aim to define specific sub-phenotypes of ARF survivors who are prone to aspiration, and to further define the faulty mechanisms underlying their dysphagia. We anticipate that these studies will facilitate the development of specific interventions that will help prevent aspiration and improve swallow efficiency.

\section{Appendix 1: FEES Protocol}

\section{Part 1 Anatomy, Secretions, Sensation, and Structural Movements,}

A. Observe all anatomic structures in view to identify anatomic or mucosal abnormalities.

B. Secretions Observe presence and location of secretions and patient response such as coughing, clearing throat, etc.

C. Movement of structures Ask patient to perform tasks that activate specific structural movements. Provide a model if needed.

Velopharyngeal closure - repeat "puh-puh-puh"

Glottic closure - cough, clear throat, hold breath (any of these)

Vocal fold and arytenoid mobility - alternate an inhale with 'eee' several times.

Arytenoid / laryngeal lift - glide up in pitch with 'eeeee' and hold it for a few seconds

Epiglottic retroflexion - observe this during bolus swallowing later in the exam when the subject is eating Pharyngeal wall medialization - produce a tight 'eee'; hold it out and squeeze your throat as you say it Base of tongue retraction - say "Paul is tall' slowly.

D. Sensory Function Lightly and briefly touch each arytenoid with the tip of the scope. Look for an immediate response; most often the laryngeal adductor reflex.

\section{Part 2: Delivery of Food and Liquid}

Bolus volumes and order of delivery Ice chips: $1 / 2$ tsp, full tsp (5 ml); Nectar thick liquid, $5 \mathrm{ml}, 15 \mathrm{ml}$; Puree (applesauce) $5 \mathrm{ml}, 10 \mathrm{ml}$; Thin liquid (water) $5 \mathrm{ml}, 15 \mathrm{ml}, 2 \mathrm{oz}$; Cracker (1/2 saltine) Thin liquid (water). $3 \mathrm{oz}$.

\section{Appendix 2 Scoring the FEES exam}

\section{Part 1 of the FEES, Prior to Food and Liquid Delivery:}

The following variables were scored as present, absent, or reduced if not otherwise specified.

- Velopharyngeal closure, vocal fold mobility, arytenoid mobility, glottic closure, epiglottic retroflexion, arytenoid lift, base of tongue retraction, pharyngeal wall medialization

- Secretions (normal, pooled outside vestibule, pooled inside the vestibule), laryngeal sensation (normal, unilateral defect, or bilateral defects).

An independent otolaryngologist scored 3 variables assessed during the Part 1 portion:

- Vocal fold mobility (abduction and adduction; complete or incomplete), presence of laryngeal edema (yes/no), presence of granulation tissue on the vocal cords (yes/ no).

\section{Part 2: The Rater Scored the Following Parameters for Every Bolus Size and Consistency Given to the Patient}

- Spillage time: from first view of bolus into hypopharynx until white out, in seconds

- Point of lowest spillage (no spillage, valleculae, lateral channels, piriform/post cricoid, laryngeal vestibule),

- Amount of residue (none/trace, mild, moderate, severe. For analyses, moderate and severe categories were combined)

- Residue location for patients with mild or moderate/ severe residue (valleculae, lateral channels, piriforms/ post cricoid, laryngeal vestibule)

- Response to residue (spontaneous clearing, ejection, no response)

- Penetration (before, during, after the swallow)

- Aspiration (before, during, after the swallow)

- PAS score (1-8) 


\section{Appendix 3}

See Table 8 .

Table 8 Association of edema with vocal fold and arytenoid mobility

\begin{tabular}{|c|c|c|c|c|}
\hline & $\begin{array}{l}\text { Normal arytenoid mobility } \\
(\mathrm{n}=167)\end{array}$ & $\begin{array}{l}\text { Reduced arytenoid mobility } \\
(\mathrm{n}=31)\end{array}$ & Absent arytenoid mobility $(\mathrm{n}=8)$ & $\mathrm{p}$ value \\
\hline Edema & & & & $<0.0001$ \\
\hline Yes & $70.1 \%(80 / 113)$ & $23.0 \%(26 / 113)$ & $6.2 \%(7 / 113)$ & \\
\hline \multirow[t]{2}{*}{ No } & $93.6 \%(87 / 93)$ & $5.4 \%(5 / 93)$ & $1.1 \%(1 / 93)$ & \\
\hline & \multicolumn{2}{|c|}{ Normal vocal cord mobility } & Reduced vocal cord mobility & \\
\hline \multicolumn{5}{|l|}{ Edema } \\
\hline Yes & $74.8 \%(89 / 119)$ & & $25.2 \%(30 / / 119)$ & 0.15 \\
\hline No & $83.0 \%(78 / 94)$ & & $17.0 \%(16 / 94$ & \\
\hline
\end{tabular}

\section{Appendix 4}

See Table 9.

Table 9 Association between sensation and presence of spillage

\begin{tabular}{lll}
\hline & $\begin{array}{l}\text { Liquid spillage } \\
\text { Yes } \\
(\mathrm{n}=150)\end{array}$ & $\begin{array}{l}\text { Liquid spillage } \\
\text { No } \\
(\mathrm{n}=25)\end{array}$ \\
\hline $\begin{array}{l}\text { Sensation } \\
\text { Yes-intact }\end{array}$ & $\begin{array}{l}81 \%(81 / 100) \\
\text { No-reduced/absent }\end{array}$ & $\begin{array}{l}\mathrm{p} \%(69 / 75) \\
\text { If positive spillage }\end{array}$ \\
\cline { 2 - 3 } & $\begin{array}{l}\text { Included laryngeal vestibule } \\
\text { Yes } \\
(\mathrm{n}=92)\end{array}$ & $\begin{array}{l}19 \%(19 / 100) \\
8 \%(6 / 75)\end{array}$ \\
\hline Sensation & $\begin{array}{l}\text { Included laryngeal vestibule } \\
\text { No } \\
\text { Yes-intact }\end{array}$ & $\mathrm{n}=52)$ \\
No-reduced/absent & $27.2 \%(22 / 81)$ & $\begin{array}{l}43.5 \%(30 / 69) \\
56.5 \%(39 / 69)\end{array}$ \\
\hline
\end{tabular}

There was no difference if patients had unilateral or bilateral loss of sensation

Funding NIH grants K24 HL 089223 and R21 NR 015886 (MM).

\section{Compliance with Ethical Standards}

Conflict of interest The authors do not have any conflicts of interest to disclose.

\section{References}

1. Vincent JL, Akca S, De MA, et al. The epidemiology of acute respiratory failure in critically ill patients. Chest. 2002;121:1602-9.
2. Wunsch H, Linde-Zwirble WT, Angus DC, Hartman ME, Milbrandt EB, Kahn JM. The epidemiology of mechanical ventilation use in the United States. Crit Care Med. 2010;38:1947-53.

3. Macht M, White SD, Moss M. Swallowing dysfunction after critical illness. Chest. 2014;146:1681-9.

4. Macht M, Wimbish T, Bodine C, Moss M. ICU-acquired swallowing disorders. Crit Care Med. 2013;41:2396-405.

5. Schefold JC, Berger D, Zurcher P, et al. Dysphagia in mechanically ventilated icu patients (DYnAMICS): a prospective observational trial. Crit Care Med. 2017;45:2061-9.

6. Brodsky MB, Levy MJ, Jedlanek E, et al. Laryngeal injury and upper airway symptoms after oral endotracheal intubation with mechanical ventilation during critical care: a systematic review. Crit Care Med. 2018;46:2010-7. 
7. Yang WJ, Park E, Min YS, et al. Association between clinical risk factors and severity of dysphagia after extubation based on a videofluoroscopic swallowing study. Korean J Intern Med. 2020;35:79-87.

8. Scheel R, Pisegna JM, McNally E, Noordzij JP, Langmore SE. Endoscopic assessment of swallowing after prolonged intubation in the ICU setting. Ann Otol Rhinol Laryngol. 2016;125:43-52.

9. Ponfick M, Linden R, Nowak DA. Dysphagia-a common, transient symptom in critical illness polyneuropathy: a fiberoptic endoscopic evaluation of swallowing study*. Crit Care Med. 2015;43:365-72.

10. Ambika RS, Datta B, Manjula BV, Warawantkar UV, Thomas AM. Fiberoptic endoscopic evaluation of swallow (FEES) in intensive care unit patients post extubation. Indian J Otolaryngol Head Neck Surg. 2019;71:266-70.

11. Ajemian MS, Nirmul GB, Anderson MT, Zirlen DM, Kwasnik EM. Routine fiberoptic endoscopic evaluation of swallowing following prolonged intubation: implications for management. Arch Surg. 2001;136:434-7.

12. Lynch YT, Clark BJ, Macht M, et al. The accuracy of the bedside swallowing evaluation for detecting aspiration in survivors of acute respiratory failure. J Crit Care. 2017;39:143-8.

13. Macht M, Wimbish T, Clark BJ, et al. Diagnosis and treatment of post-extubation dysphagia: results from a national survey. J Crit Care. 2012;27:578-86.

14. Macht M, Wimbish T, Clark BJ, et al. Postextubation dysphagia is persistent and associated with poor outcomes in survivors of critical illness. Crit Care. 2011;15:R231.

15. Zuercher P, Moret CS, Dziewas R, Schefold JC. Dysphagia in the intensive care unit: epidemiology, mechanisms, and clinical management. Crit Care. 2019;23:103.

16. Colton HJ, Noordzij JP, Murgia B, Langmore S. Laryngeal injury from prolonged intubation: a prospective analysis of contributing factors. Laryngoscope. 2011;121:596-600.

17. Francois B, Bellissant E, Gissot V, et al. 12-h pretreatment with methylprednisolone versus placebo for prevention of postextubation laryngeal oedema: a randomised double-blind trial. Lancet. 2007;369:1083-9.

18. Brodsky MB, De I, Chilukuri K, Huang M, Palmer JB, Needham DM. Coordination of pharyngeal and laryngeal swallowing events during single liquid swallows after oral endotracheal intubation for patients with acute respiratory distress syndrome. Dysphagia. 2018;33(6):768-77.

19. Knaus WA, Draper EA, Wagner DP, Zimmerman JE. APACHE II: a severity of disease classification system. Crit Care Med. 1985;13(10):818-29.

20. Charlson ME, Pompei P, Ales KL, MacKenzie CR. A new method of classifying prognostic comorbidity in longitudinal studies: development and validation. J Chronic Dis. 1987;40(5):373-83.

21. Langmore SE. History of Fiberoptic Endoscopic Evaluation of Swallowing for evaluation and management of pharyngeal dysphagia: changes over the years. Dysphagia. 2017;32:27-38.

22. O'Dea MB, Langmore SE, Krisciunas GP, et al. Effect of lidocaine on swallowing during FEES in patients with dysphagia. Ann Otol Rhinol Laryngol. 2015;124:537-44.

23. Kaneoka A, Pisegna JM, Inokuchi H, et al. relationship between laryngeal sensory deficits, aspiration, and pneumonia in patients with dysphagia. Dysphagia. 2018;33:192-9.

24. Jafari S, Prince RA, Kim DY, Paydarfar D. Sensory regulation of swallowing and airway protection: a role for the internal superior laryngeal nerve in humans. J Physiol. 2003;550:287-304.

25. Domer AS, Kuhn MA, Belafsky PC. Neurophysiology and clinical implications of the laryngeal adductor reflex. Curr Otorhinolaryngol Rep. 2013;1:178-82.

26. Kaneoka AS, Langmore SE, Krisciunas GP, Field K, Scheel R, McNally E, Walsh MJ, O’Dea MB, Cabral H. The boston residue and clearance scale: preliminary reliability and validity testing. Folia Phon Logo. 2013;65:312-7.
27. Rosenbek JC, Robbins JA, Roecker EB, Coyle JL, Wood JL. A penetration-aspiration scale. Dysphagia. 1996;11:93-8.

28. Skoretz SA, Flowers HL, Martino R. The incidence of dysphagia following endotracheal intubation: a systematic review. Chest. 2010;137:665-73.

29. Borders JC, Fink D, Levitt JE, et al. Relationship between laryngeal sensation, length of intubation, and aspiration in patients with acute respiratory failure. Dysphagia. 2019;34:521-8.

30. Fuller SC, Leonard R, Aminpour S, Belafsky PC. Validation of the pharyngeal squeeze maneuver. Otolary Head Neck Surg. 2009. https://doi.org/10.1016/j.otohns.2008.12.015.

31. Miloro KV, Pearson WG, Langmore SE. Effortful Pitch Glide: a potential new exercise evaluated by Dynamic MRI. J Speech Lang Hear Res. 2014;57(4):1243-50.

32. Krisciunas GP, Langmore SE, Gomez-Taborda S, et al. The association between endotracheal tube size and aspiration (During Flexible Endoscopic Evaluation of Swallowing) in acute repiratory failure survivors. Crit Care Med. 2020. https://doi. org/10.1097/CCM.0000000000004554.

33. Logemann JA, Kahrilis PJ, Cheng J, et al. Closure mechanisms of laryngeal vestibule during swallow. Am J Physiol. 1992;262:G338-44.

34. Dua KS, Ren J, Bardan E, Xie P, Shaker R. Coordination of deglutitive glottal function and pharyngeal bolus transit during normal eating. Gastroenterology. 1997;112:73-83.

35. Palmer JB, Rudin NJ, Lara G, Crompton AW. Coordination of mastication and swallowing. Dysphagia. 1992;7:187-200.

36. Logemann JA, Pauloski BR, Rademaker AW, Colangelo LA, Kahrilas PJ, Smith CH. Temporal and biomechanical characteristics of oropharyngeal swallow in younger and older men. J Speech Lang Hear Res. 2000;43:1264-74.

Publisher's Note Springer Nature remains neutral with regard to jurisdictional claims in published maps and institutional affiliations.

Susan E. Langmore PhD, CCC-SLP

Gintas P. Krisciunas MPH, MA

Heather Warner PhD, CCC-SLP

\section{S. David White CCC-SLP}

Daniel Dvorkin $\mathrm{PhD}$

Daniel Fink MD

Edel McNally MS, CCC-SLP

Rebecca Scheel MS, CCC-SLP

Carrie Higgins BSN

Joseph E. Levitt MD, MS

Jeffrey McKeehan MS

Sandra Deane MS

Jonathan M. Siner MD

Rosemary Vojnik BS

Marc Moss MD 